\title{
Prevalence and molecular characterization of $\beta$-lactamase resistance gene in multidrug resistance bacteria, Proteus spp.
}

\author{
Sabiha S. Salih \\ Laboratory department \\ College of Health \\ Sulaimani Polytechnic University \\ Sulaimani, raq \\ Sabiha.salih@spu.edu.iq \\ Lana MA Mohammed \\ Laboratory department \\ College of Health \\ Sulaimani Polytechnic University \\ Sulaimani/Iraq \\ Lana.amin@spu.edu.iq
}

\author{
Shno J. Mohammed \\ Bacteriology department \\ Central laboratory \\ Sulaimani Teaching Hospital \\ Sulaimani,Iraq \\ Muhamad.shno@yahoo.com
}

\author{
Imad M Noori
Nursing department
College of Health
Sulaimani Polytechnic University
Sulaimani,Iraq
Emadmajeed87@gmail.com \\ Imad M Noori
Nursing department
College of Health
Sulaimani Polytechnic University
Sulaimani,Iraq
Emadmajeed87@gmail.com \\ Imad M Noori
Nursing department
College of Health
Sulaimani Polytechnic University
Sulaimani,Iraq
Emadmajeed87@gmail.com \\ Imad M Noori
Nursing department
College of Health
Sulaimani Polytechnic University
Sulaimani,Iraq
Emadmajeed87@gmail.com \\ Imad M Noori
Nursing department
College of Health
Sulaimani Polytechnic University
Sulaimani,Iraq
Emadmajeed87@gmail.com \\ Imad M Noori
Nursing department
College of Health
Sulaimani Polytechnic University
Sulaimani,Iraq
Emadmajeed87@gmail.com
}

Taib A Hama Soor

Laboratory department College of Health

Sulaimani Polytechnic University

Sulaimani/Iraq

taib.ahmed@spu.edu.iq

\begin{abstract}
3rd International
Conference on Health \&

Medical Sciences: Insight into Advanced Medical Research (ICHMS 2019)
\end{abstract}

DOI:

10.24017/science.2019

.ICHMS.2

Received:

9 May 2019

Accepted:

23 June 2019

\section{Abstract}

Existing of drug resistance bacteria in meat is a series health concern and b-lactamase is responsible to generate multi drug resistances in bacteria. Meat is a source of delivering food born pathogen bacteria including Proteus species. Recently Proteus bacteria developed drug resistance against many antimicrobial drugs and it causes difficulty in patient's treatment. Hence its important to indicate the rate of Proteus species, $P$. mirabilis and $P$. Vulgaris, in meat of different animals and to find the prevalence of b-lactamase resistance genes (blaTEM-1, blaCMY, blaCMY2, blaShv, blaOXA, and blaCTX) in Proteus species. Molecular identification of Proteus bacteria was confirmed by PCR amplification of part of 16S rRNA using Proteus specific set of primers. 70 meat samples (cattle, sheep, chicken, turkey, goat, and fish) were collected in local meat shops in the center of Sulaimani city. 29 (41.4\%) samples were positive to Proteus species and 22 (75.87\%) isolates were $P$. mirabilis and seven (24.13\%) were $P$. vulgaris based on conventional biochemical tests. The drug sensitivity test was performed for all isolates using a disk diffusion assay (Kirby Bauer test). The multi drug resistance were found in all isolates and the most common drug resistance phenotype were against tetracycline, rifampin, and doxycycline, while the imepenem, tobramycin, and meropenem remain more affective against the bacteria. Resistance genes, blaTEM-1 and blaShv were found in five 


\begin{abstract}
isolates (17.2\%) of Proteus. Three isolates (10.3\%) were positive to blaTEM-1 resistance gene and two isolates (6.8\%) were positive to blaShv. All resistance genes recorded in this study were recovered in $P$. mirabilis and none of them was reported in $p$. vulgaris. None of the isolates was positive to $b$ lactamase genes, blaCMY, blaCMY2, blaOXA, and blaCTX.
\end{abstract}

Keywords: Meat born pathogen, Proteus spp., Antibiotic sensitivity test, Resistance genes, $\beta$-lactamase.

\title{
1. INTRODUCTION
}

Increasing bacterial resistance against common antibacterial drugs is a series health concern and appearing and exchanging antimicrobial resistance among different bacteria makes a complex problem. Bacteria gain resistance because of different factors and the most common one is existing of drug resistance genes and improper using of antibiotics [1]. In animal industry, antibiotic has been used to promote animal growth in addition to therapeutic and prophylactic purposes [2]. The development of drug resistance in pathogen bacteria that due to the heavy consuming of antibacterial medicines is very well studied. Animal meat is a good source of nutrition to bacteria, so it becomes a grate reservoir of pathogenic bacteria including Salmonella species, Shiga toxin producing E. coli strains, and Proteus [3, 4, 5].

The zoonotic properties of food born bacteria in combination with producing toxin and bearing resistance genes accelerate the seriousness of the diseases and even death in untreatable cases. Millions of cases that resulted from food born pathogens have been recorded yearly globally in sporadic patients and even in outbreak cases in some countries. The outcome of the diseases can be seen in appearing of a million diarrhea symptom in children due to enteropathogenic bacteria and about three million death casualties annually [5].

Beta-lactam antibiotics are a commonly used antibiotics against different gram negative bacteria. AmpC $\beta$-lactamases is an enzyme generated by bacteria and it woks to lyse beta lactam class antibiotics. AmpC betalactamse has been studied well for more than forty years since a drug resistance gene discovered in gram negative bacteria against beta-lactam. Bacteria produce betalactamse to fight against beta lactam antibiotic as a strategy to survive [6, 7]. Its important to study and investigate AmpC beta lactamase, specifically in medical aspects because of its ability to deactivate many types of commonly used antibacterial including cephalosporins, penicillins, cephamycins, oxyimino-cephalosporins, and monobactams [6].

The disability of extended spectrum beta lactamases (ESBL) inhibitor clavulanic acid against betalactamse gene favour bacteria to have stronger resistance pattern against ESLB and beta lactam antibacterial drug. AmpC $\beta$-lactamase proteins can be expressed from either chromosome or plasmid. Many bacteria express the enzyme chromosomally including Shigella, Enterobacter, Serratia marcescens, Enterobacter cloacae, Citrobacter freundii, Hafnia alvei, Pseudomonas aeruginosa, Morganella morganii. Escherichia coli, and Acinetobacter species Laghawe Avinash et al., 2012, [7, 8, 9].

The plasmid bearing AmpC beta lactamse gene is expressed constitutively, while some of them expressed through beta lactam induction similar to chromosomal gene. The spreading of plasmid bearing AmpC resistance gene is easier than chromosomal gene and this makes plasmid AmpC beta lactamase gene to be clinically more important. Enterobacteriacae exchange plasmid bearing resistance gene continuously to develop resistance against beta lactam antibacterial medicines such as in Salmonella spp., Klebsiella spp., Proteus mirabilis, and Escherichia coli [10].

In some gram negative bacteria, the occurrence of AmpC beta lactamase is high but its not well studied in Proteus species especially in sulaimani city. Proteus recently shows resistance against many antibacterial medicines and this cannot be detected accurately through regular antibiotic sensitivity test phenotypically and its not guided by Clinical and Laboratory Standards 
Institute (CLSI) until now [11, 12].

Polymerase chain reaction (PCR) has been developed to amplify and rapid identification of resistance genes [13]. This method can be used to detect six different beta lactamase genes in gram negative bacteria, Proteus species including blaTEM-1, blaCMY, blaCMY2, blaShv, blaOxa, and blaCTX $[13,14,15]$. The aim of this study was to 1- finding the rate of Proteus species in raw meat of different animals in local meat shops. 2- to find multi drug resistance pattern of Proteus against commonly used antimicrobials. 3- to detect the existing beta lactamase resistance genes in Proteus species.

\section{METHODS AND MATERIALS}

\section{Sample collection}

A total of 70 meat samples (Beef, Sheep, Turkey, Chicken, Fish) were collected from local meat shops in the centre of Sulaimany city from December 2018 to January 2019. Every single sample was purchased from different shop to collect a variety of samples and represent different types and sources of bacterial contamination. The samples were put into a sterile container and kept cold at $4-10^{\circ} \mathrm{C}$ until they are arrived to the laboratory for further processing.

\section{Sample processing}

For every sample, $10 \mathrm{gm}$ of the meat sample was weighed and homogenised in $90 \mathrm{ml}$ of nutrient broth using sterile blender. The homogenised meat was put into a flask container and was then incubated for 16 hours at $37^{\circ} \mathrm{C}$ in shaking incubator.

\section{Isolation and Identification of Proteus species}

All culture media and biochemical tests were purchased from Accumedia LAB (Neogene Culture Media, Heywood, UK). For isolation of gram negative bacteria, Proteus species, approximately $20 \mu \mathrm{l}$ of the overnight culture was taken and streaked on MacConkey`s agar and incubated at $37^{\circ} \mathrm{C}$ overnight.

The colonies were taken and streaked again on nutrient agar to detect swarming properties after overnight incubation at $37^{\circ} \mathrm{C}$. The samples from swarming were taken to obtain a typical colony on MacConkey`s agar. After incubation, a colonies were taken and transfer to the MacConkey`s agar containing swarming inhibition substance to further confirmation of the Proteus species swarming characteristic.

\section{Molecular Identification of Proteus species}

\section{DNA Extraction}

A fresh single colony was dissolved in $100 \mathrm{ul}$ of sterilized distilled water and the mixture was boiled at $99^{\circ} \mathrm{C}$ for 15 minutes using thermo-cycler heating blocks (Applied biosystem 2727, California, USA). Two ul of the boiled bacteria was used as DNA template for PCR amplification of the gene of interest.

\section{Polymerase Chain Reaction for the Detection of Proteus species}

For specific molecular detection of Proteus bacteria, 16s rRNA gene (201 bp) was PCR amplified using oligoes and protocols according to [16]. The PCR volume of $20 \mu \mathrm{l}$ was used for PCR reaction and it was containing a mixture of $10 \mu \mathrm{l}$ of $2 \mathrm{X}$ premix RedTaq DNA polymerase (SBSbio, Beijing, China), $0.5 \mu \mathrm{M}$ of each primers and $2 \mu \mathrm{l}$ of DNA template (boiled colonies). The PCR running condition was started at temperature of $94^{\circ} \mathrm{C}$ for $5 \mathrm{~min}$, and 35 cycles of $94^{\circ} \mathrm{C}$ $30 \mathrm{Sec}, 55^{\circ} \mathrm{C} 30 \mathrm{Sec}, 72^{\circ} \mathrm{C} 30 \mathrm{Sec}$, with the final extension temperature $72^{\circ} \mathrm{C}$ for 7 minutes. The PCR products were then fractionated on 1\% agarose gel using DNA gel electrophoresis and visualized by blue light excitation of fluorescence dye, GoodView (SBSbio, Beijing, China) using SmartDoc 2.0 Imaging System (Accuris, NJ, USA) 


\section{Identification of Proteus species, P. vulgaris and P. mirabilis}

After PCR confirmation of Proteus bacteria, Simmons citrate test was used to identify Proteus species. A fresh single colony was incubated into a slant agar of Simmons citrate and the culture was incubated aerobically at $37^{\circ} \mathrm{C}$ for 24 hours. The selection depended on changing color from green to blue for positive biochemical reaction (citrate utilization) in the presence of Proteus mirabilis and not color change (no citrate utilization) for negative result in the case of $P$. vulgaris [17].

\section{Antibiotic sensitivity test}

Antibiotic sensitivity test was performed using Kirby Bauer test (disk diffusion test) according to the protocol described by the CLSI (2002) [12]. Antibiotic sensitivity test was performed for 13 different antimicrobials as follow, amoxicillin (AX 25), Tobramycin (TOB 10), amoxicillinclavulanic acid (AMC 30), Tetracycline (TE 10), Doxycycline (DO 10), Imipemem (IMP 10), trimethoprim/sulfamethoxazole (SXT 25), meropenem (MEM 10), Ciprofloxacine (CIP 10), gentamycin (CN 10), Rifampin (RA 5), amikacin (AK 10), and cefotaxime (CTX 30).

The antibiotic disks were purchased from Bioanalyse Pharmaceutical (Bioanalyse, Ankara, Turkey) and the results were interpreted according to the clear zone diameter measured around the disc according to the manufacturer chart.

\section{Polymerase Chain Reaction of $\beta$-lactamase resistance genes \\ PCR amplification for six $\beta$-lactamase resistance genes (blaTEM-1, blaCMY, blaCMY2, blaShv, blaOxa, and blaCTX) was carried out using multiplex PCR. Multiplex PCR was divided into two groups, G1 were blaTEM-1, blaCMY, blaCMY2, and G2 were blaShv, blaOxa, and blaCTX. The universal primers were taken and used according to $[15,18]$. The PCR mixture was carried out in $20 \mu \mathrm{l}$ volume reaction containing $10 \mathrm{ul}$ 2X RedTag DNA polymerase premix, $0.2 \mu \mathrm{M}$ of each primer, and $2 \mu \mathrm{l}$ of DNA extracted from boiled colonies. The PCR was run under the following condition, it started with $94^{\circ} \mathrm{C}$ for $5 \mathrm{~min}$, and 35 cycles of $94^{\circ} \mathrm{C} 30 \mathrm{Sec}$, $55^{\circ} \mathrm{C} 30 \mathrm{Sec}, 72^{\circ} \mathrm{C} 30 \mathrm{Sec}$, with the final extension temperature $72^{\circ} \mathrm{C}$ for 7 minutes using thermo cycler (Applied Biosystems 2727, Calif., U.S.A.). \\ The reaction DNA product was resolved on 1\% DNA agarose gel, stained with GoodViw fluorescence DNA stain (SbsBio, Beijing, china) and visualized under blue light transilluminator using SmartDoc 2.0 Imaging System (Accuris, NJ, USA).}

\section{RESULTS}

\section{Prevalence of Proteus vulgaris and Proteus mirabilis}

A total number of 70 meat samples were processed. The samples were collected from different animal and organs including beef 10 samples, sheep 10 samples, goat 10 samples, turkey 10 samples, fishes 10 samples, chicken 10 samples, and chicken liver 10 samples. Out of these samples 29 (41.4\%) isolates were confirmed as Proteus bacteria by swarming properties of Proteus and specific PCR confirmation of $16 S$ rRNA (201 bp) (Figure 1). Meat is a good source of nitrogen, carbon and energy so it considers as a good reservoir for pathogen bacteria. Many pathogen bacteria can grow on meat and become a source of food born bacterial diseases in human.

Simmons citrate test was undertaken to identify two species of Proteus, $P$ mirabilis and $P$. vulgaris, based on ability of bacterial species to utilize citrate. $P$. mirabilis recorded the highest rate in meat (22 isolates, $75.87 \%$ ) in compare to $P$. vulgaris (seven isolates, 24.134\%) (Figure $1)$. 

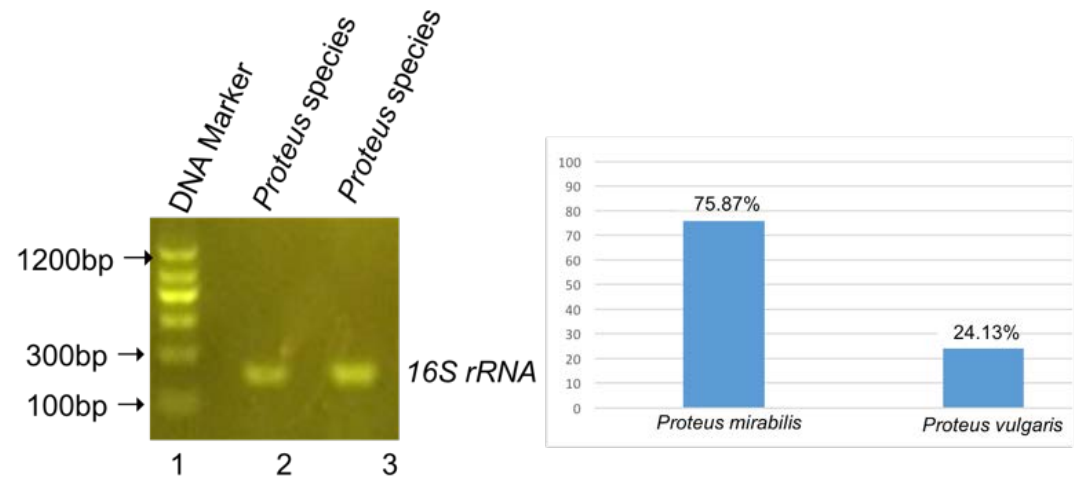

Figure 1. Identification and the rate of Proteus species in raw meat. PCR confirmation of Proteus bacteria (The left image). The percentage of $P$. mirabilis and $p$. vulgaris in raw meat (The right image).

\section{Antibiotic Susceptibility Examination}

Antibiotic susceptibility test was carried out using Kirby-Bauer disc diffusion test on Muller Hinton agar. The pattern of Antibiotic Susceptibility testing of isolates were different in their susceptibility against 13 common antibacterial discs (Figure 2). All isolates showed 100\% resistance to three antimicrobials, tetracycline, rifampin, and doxycycline. Multi drug resistance were found in all isolates for many types of antimicrobial especially tetracycline, rifampin, and doxycycline, and tobramycin. The overall antibiotic resistance pattern of Proteus bacteria was like the following; tetracycline (100\%), rifampin (100\%), and doxycycline (100\%), gentamycin (65.5\%), tobramycin (62\%), amoxicillin (93.1\%), amoxicillin-clavulanic acid (82.7\%), Imepemem (68.9\%), trimethoprim/sulfamethoxazole (93.1), meropenem (65.5\%), Ciprofloxacine (68.9\%), amikacin (65.5\%). Amikacin, imepenem, and ciprofloxacin remained active against Proteus and most of Proteus species showed the highest rate of susceptibility to them.

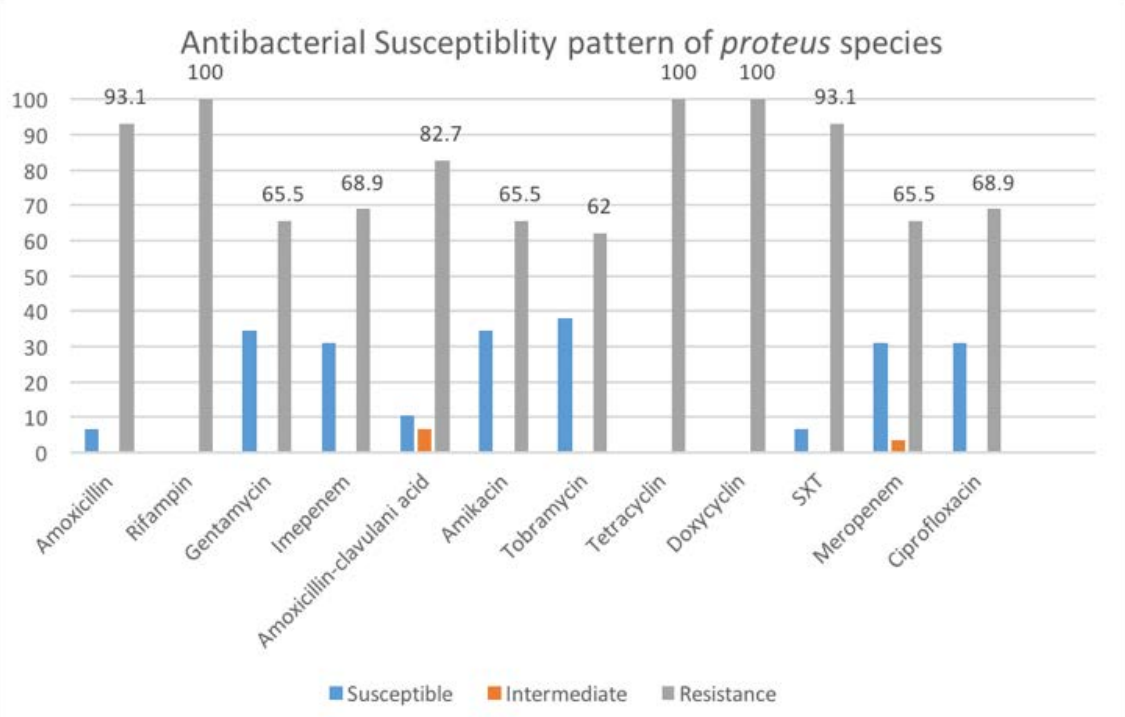

Figure 2. Antibiotic susceptibility pattern of Proteus species isolated from different raw meat in local meat shops in Sulamiani city. 


\section{Prevalence of $\beta$-lactamase resistance genes}

Existing of $\boldsymbol{\beta}$-lactamase genes in gram negative bacteria enable the bacteria to express $\beta$ lactamase enzyme to hydrolyze and deactivate common $\beta$-lactam ring of antibiotics, cephalocporins and ampicillin [6]. This leads to developing bacterial resistance against these antibiotics. Among $\beta$-lactamase resistance genes, SHV, CTX-M, TEM, CMY, CMY2, and OXA are the most common and well documented [19]. This study investigated the existence of these resistance genes in $P$. mirabilis and $P$. vulgaris by PCR amplification of their conservative region using gene specific set of primers.

\section{blaCMY, blaCMY2, blaOxa, and blaCTX}

PCR amplification was carried out to find different $\beta$-lactamase resistance genes using universal gene specific primers. All Proteus isolates showed negative result to four types of $\beta$-lactamase resistance genes, blaCMY, blaCMY2, blaOxa, and blaCTX. So none of the isolates carry these types of resistance genes on their chromosome and plasmids.

\section{blaTEM}

Out of 29 Proteus isolates, three isolates (10.3\%) were positive to one type of $\beta$-lactamase resistance genes, blaTEM (1080 bp) (Figure 3). All three resistance genes were found in $P$. mirablis $(100 \%)$ and blaTEM was not recorded in P. vulgaris (0\%). Two isolates bearing blaTEM showed multidrug resistance to many beta lactam antibiotics, amoxicillin and amoxicillin-clavulanic acid and one isolates showed the resistance pattern to another new generation of $\beta$-lactam of antibiotics, cefotaxime.

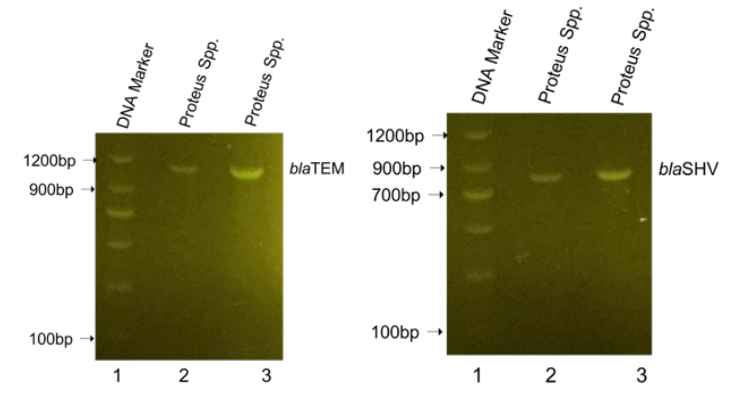

Figure 3. PCR amplification of blaTEM and blaSHV resistance genes in Proteus species. The amplicons were resolved on 1\% DNA agarose gel and the size of the genes were compared to the DNA ruler of 1.2 $\mathrm{Kb}$.

\section{blaSHV}

blaSHV resistance gene (797 bp) was found in two Proteus isolates (6.8\%) (Figure 3). All positive isolates to blaSHV belonged to $P$. mirabilis (100\%). One of the $P$. mirabilis expressing the enzyme of blaSHV gene became resistance against amoxicillin-clavulanic and cefotaxime, and amoxicillin, but the second isolate is still sensitive to extended spectrum and new generation of $\beta$-lactam, amoxicillin-clavulanic acid and cefotaxime, respectively.

\section{DISCUSSION}

Meat of animal is sterile and does not contain any bacteria [20], but it can be contaminated after slaughtering. The sources of meat contamination are variable starting from post slaughter processing until it arrives to the markets and home kitchens. Bacterial contamination may come from intestinal content of the the animal during visceral removal or sources from environment including butcher's hands, tools and transportation equipments [21, 22, 23]. Meat is a good source of food, carbon, nitrogen and energy, for bacteria growth and meat bearing pathogens leads to transmitting of pathogens to human, causeing infection and intoxication [24]. Proteus is one of the bacterial pathogens that transmit from animal meats and causes infection in human. 
It has been found through different studies that food born Proteus leads to diseases in human such as UTI, rheumatic arthritis, and hospital acquired wound infection [25, 26, 27].

In this study, the rate of Proteus in animal meat was $75.8 \%$ and it shows the risk of zoonotic diseases in Sulaimani city. Meat of different animals contains Proteus species and it shows the existence of zoonotic pathogen in markets and makes a public health concern. The common type of Proteus in meat in Sulamani city was P. mirabilis, $75.8 \%$. Proteus mirabilis is one of the common causes of a hospital acquired human infection among other Proteus species so it attracts a public health concern more than other species [27]. This study agrees with other international studies that $P$. mirabilis is the most common species in raw meat of different animals [28, 29, 30, 31].

Isolates of Proteus in this study showed a complete resistance $(100 \%)$ to the most common antibiotics, tetracycline, rifampin, and doxycycline. In addition, multi drug resistance were found in all isolates for many types of antimicrobial especially tetracycline, rifampin, and doxycycline, and tobramycin. A high percentage of bacterial resistance towards tetracycline is comparable with previous studies [32, 33]. Appearing drug resistances against trimethoprim/sulfamethoxazole) and ciprofloxacine is of significantly important because they are known to be used as common and very affective antibacterial agents against gram negative bacteria [19]. Similar multi drug resistance have been found against other gram negative bacteria globally [34, 35]. Moreover, resistance was found in this study against common $\beta$ lactam antibiotics, amoxicillin, amoxicillin-clavulanic acid. This is significantly important because these antibiotics are used against wide ranges of Proteus infection in human [36].

The existence of $\beta$-lactamase gene is significantly important and it's a health concern. This enzyme destroys $\beta$-lactam ring of antibiotics and enable the bacteria to resist common $\beta$-lactam ring antibiotics. Six of these resistance genes were known as common $\beta$-lactamase resistance genes, (blaTEM-1, blaCMY, blaCMY2, blaShv, blaOXA, and blaCTX) [19] and they were investigated in this study in Proteus species. A specific set of primers used to amplify these genes specifically using polymerase chain reaction in two groups of multiplex PCR. Out of 29 Proteus isolates, three isolates (10.3\%) were positive to blaTEM and two isolates (6.8\%) were positive to blaSHV resistance genes. All five resistance genes were found in $P$. mirablis (100\%) and none of them was recorded in $P$. vulgaris $(0 \%)$. None of the other four resistance genes, blaCMY, blaCMY2, blaOxa, and blaCTX, was reported in this study. Isolates bearing blaTEM and blaSHV showed multidrug resistance to many beta lactam antibiotics, amoxicillin and amoxicillin-clavulanic acid cefotaxime. So in this study, blaTEM and to blaSHV were the commonly reported resistance genes are in Proteus species and they exist only in $P$. mirabilis. The rate of $\beta$-lactamase genes is less common in Proteus species than in other gram negative bacteria [37, 38]. This study agrees with previous finding to report the presence of $\beta$-lactamase genes in Proteus species [39, 40]. In general, there were no $\beta$-lactamase resistance genes reported in many studies [37] or its less commonly reported [34], but five isolates of Proteus (17.2\%) were found in Sulaimany city. This is clinically importance and it is alarming because it hits the value of many $\beta$-lactam antibiotics and impose the patients to face difficulty in treatment. This study strongly agrees with the finding in Karbala city in Iraq which reported the highly occurrence of both resistance genes, blaTEM and blaSHV, in Proteus mirablis [41].

\section{CONCLUSION}

The result of the current study showed that the rate of contamination of meat with Proteus species was $41.1 \%$ and the most common species is Proteus mirabilis. Proteus showed a complete resistance to many antibacterial agents and multi drug resistanc including tetracycline, rifampin, and doxycycline. Bacteria showed less resistance to imepenem, tobramycin, gentamycin, and meropenem. Both $\beta$-lactam resistance genes, blaTEM and to blaSHV, were found in Proteus species and blaTEM is the most common one. All $\beta$-lactam resistance genes found in this study was reported only in $P$. mirabilis. None of the Proteus isolates were positive to blaCMY, blaCMY2, blaOXA, and blaCTX. 


\section{REFERENCES}

[1] World Health Organization, “Global strategy for containment of antimicrobial resistance,” Geneva: World Health Organization. Publication WHO/CDS/CSR/DRS/2001.2a, 2001.

[2] FM. Aarestrup, "Veterinary drug usage and antimicrobial resistance in bacteria of animal origin,” Basic Clin Pharmacol Toxicol 96:271- 81, 2005.

[3] MN. Swartz, "Human diseases caused by foodborne pathogens of animal origin," Clin Infect Dis 34(Suppl 3):S111-22.

[4] EFSA, "The European Union summary report on trends and sources of zoonosis, zoonotic agents and food-borne outbreaks in 2013,” EFSA J 2015; 13:3991, 2013.

[5] EFSA-ECDC, "European food safety authority and European Centre for disease prevention and control," The European union summary report on trends and sources of zoonoses, zoonotic agents and food-borne outbreaks in 2015. EFSA J 2016;14, 2015.

[6] G. Col Naveen, AK. Sahni, Col S. Bhattacharya (Retd.), "Therapeutic challenges of ESBLS and AmpC beta-lactamase producers in a tertiary Care center,” Med. J. Armed Forces India, 6(9): 4 10, 2013.

[7] A. Bauernfiend Y. Chong, and S. Schweighart, "Extended broad spectrum $\beta$ lactamase in Klebsiella pneumonia incuding resistance to cephamycins,” Infection 17:316- 321,1989.

[8] SA. El-Hady, LA, Adel, “Occurrence and detection of AmpC b-lactamases among Enterobacteriaceae isolates from patients at Ain Shams University Hospital'” Egypt. J. Med. Hum. Genetics, 16: 239 244, 2015.

[9] AR. Laghawe, NK. Jaitly, VR. Thombare, "Prevalence of AMPC Betalactamase in Gram- negative bacilli,” JPBMS, 20 (07), 2012.

[10] GA. Jacoby, “AmpC -lactamses. Clin. Microbiol,” Rev. 22:161-182,2009.

[11] KH. Rand, B. Turner, H. Seifert, C. Hansen, JA. Johnson, A. Zimmer, “Clinical laboratory detection of AmpC beta-lactamase: does it affect patient outcome?,” Am J Clin Pathol, vol. 135 (pg. 572-6), 2011.

[12] Clinical and Laboratory Standards Inst.,"Performance standards for antimicrobial disk and dilution susceptibility tests for bacteria isolated from animals. Approved standard,” 2nd ed. NCCLS document M31-A2. Wayne, Pa.: CLSI, 2002.

[13] FJ. P'erez-P'erez, and ND. Hanson, "Detection of plasmid mediated AmpC $\beta$ lactamase genes in clinical isolates by using multiplex PCR,”Journal of Clinical Microbiology,” vol. 40, pp. 2153-2162, 2002.

[14] N. Fam, D. Gamal , M et al. El Said, "Prevalence of plasmidmediated ampC genes in clinical isolates of Enterobacteriaceae from Cairo, Egypt,” British Microbiology Research Journal, vol. 3, no. 4, pp. 525-537, 2013.

[15] AM. Ahmed, Y. Motoi, M. Sato, A. Maruyama, H. Watanabe, Y. Fukumoto, T. Shimamoto, "Zoo animals as a reservoir of gram-negative bacteria harboring integrons and antimicrobial resistance genes,” Appl EnvironMicrobiol 73:6686-90, 2007.

[16] E. Tajbakhsh, S. Tajbakhsh, F. Khamesipour, "Isolation and molecular detection of Gram negative bacteria causing urinary tract infection in patients referred to Shahrekord hospitals, Iran,” Iranian Red Crescent Medical J. 17(5): e24779, 2015.

[17] GI. Barrow, and RKA. Feltham, "Cowan and Steel's manual for the identification of medical bacteria,” Cambridge University Press, 3rd ed, 2003.

[18] AM. Ahmed, H. Shimabukuro, T Shimamoto, "Isolation and molecular characterization of multidrug-resistant strains of Escherichia coli and Salmonella from retail chicken meat in Japan. J Food Sci 74: M405-M410, 2009b.

[19] PA. Bradford, "Extended-spectrum $\beta$-lactamases in the 21st century: characterization, epidemiology, and detection of this important resistance threat," Clin Microbiol Rev 14:933-51, 2001.

[20] PD. Warriss, “Meat Science: An Introductory Text,” CAB-International, Wallingford, England,pp: 1-297, 2000.

[21] F. Adzitey, and N. Huda, "Effects of post-slaughter carcass handling on meat quality,” Pak. Vet. J., 32: 161-164, 2012.

[22] F. Adzitey, "MiniReview: Effect of pre-slaughter animal handling on carcass and meat Quality,” Int. Food Res. J., 18: 485-491, 2011.

[23] F. Adzitey, and H. Nurul, "Pale Soft Exudative (PSE) and Dark Firm Dry (DFD) meats:Causes and measures to reduce these incidences-a mini review,"Int. Food Res. J., 18: 11-20, 2011.

[24] RK. Pundir and P. Jain, "Evaluation of five chemical food preservatives for their antibacterial activity against bacterial isolates from bakery products and mango pickles,” J. Chem. Pharm. Res. 3(1): 24-31, 2011.

[25] A. Ebringer, T Rashid, "Rheumatoid arthritis is caused by a Proteus urinary tract infection,” APMIS 122: 363-368, 2014.

[26] CE. Armbruster, SN. Smith, A Yep, HL. Mobley, “Increased Incidence of Urolithiasis 
and Bacteremia During Proteus mirabilis and Providencia stuartii Coinfection Due to Synergistic Induction of Urease Activity,” The J. of infectious diseases 209: 15241532, 2014.

[27] SM. Jacobsen, DJ. Stickler, HL. Mobley, ME. Shirtliff, "Complicated catheter associated urinary tract infections due to Escherichia coli and Proteus mirabilis," Clinical microbiology reviews 21: 26-59, 2008.

[28] SD. Park, Y. Uh, G. Lee, K. Lim, JB. Kim, et al., "Prevalence and resistance patterns of extended-spectrum and AmpC beta-lactamase in Escherichia coli, Klebsiella pneumoniae, Proteus mirabilis, and Salmonella serovar Stanley in a Korean tertiary hospital,” APMIS 118: 801-808, 2010.

[29] M. Tonkic, B. Mohar, K. Sisko-Kraljevic, K. Mesko-Meglic, I. Goic-Barisic, et al., "High prevalence and molecular characterization of extended-spectrum betalactamase-producing Proteus mirabilis strains in southern Croatia,” Journal of medical microbiology 59: 1185-1190, 2010.

[30] LM. Aragon, B. Mirelis, E. Miro, C. Mata, L. Gomez, A. Rivera, P. Coll, F. Navarro "Increase in beta-lactam-resistant Proteus mirabilis strains due to CTX-M- and CMYtype as well as new VEB- and inhibitor- resistant TEM-type beta-lactamases,” The Journal of antimicrobial chemotherapy 61: 1029-1032, 2008.

[31] SH. Kim, CI. Wei, H. An, "Molecular characterization of multidrug-resistant Proteus mirabilis isolates from retail meat products,” J. of food protection 68: 1408-1413, 2005.

[32] N. Arifatun, S. Mashuk, N. Shamsun, SA. Kazi, A. Sk Imran, and I. Salequl, "Multidrug Resistant-Proteus Mirabilis Isolated from Chicken Droppings in Commercial Poultry Farms: Bio-security Concern and Emerging Public Health Threat in Bangladesh,” J Biosafety Health Educ 2:120, 2014.

[33] Magalhaes VD, Schuman W, Castilho BA. (1998). A new tetracycline resistance determinant cloned from Proteus mirabilis. Biochim Biophys Acta 1443: 262-266, 1998.

[34] M. Sunde, "Prevalence and characterization of class 1 and class 2 integrons in Escherichia coli isolated from meat and meat products of Norwegian origin,” J Antimicrob Chemother 56:1019-24, 2005.

[35] JJ. Yan, CY. Hong, WC. Ko, YJ. Chen, SH. Tsai, CL. Chuang, JJ. Wu, “Dissemination of blaCMY-2 among Escherichia coli isolates from food animals, retail ground meats, and humans in southern Taiwan,” Antimicrob Agents Chemother 48:1353-6, 2004

[36] MH. Wong, HY Wan, S. Chen S, “Characterization of multidrug-resistant Proteus mirabilis isolated from chicken carcasses,” Foodborne pathogens and disease 10: 177-181, 2013.

[37] S. Hiva, AN. Neda, GT. Arash, B. Zohre, A. Alireza, and Y. Rouzbeh, "Prevalence of AmpC _-lactamase in Clinical Isolates of Escherichia coli, Klebsiella spp., and Proteus mirabilis in a Tertiary Hospital in Tehran, Iran,” Jundishapur J Microbiol:9(12):e39121, 2016.

[38] PE. Coudron, ES. Moland, KS. Thomson, “Occurrence and detection of AmpC betalactamases among Escherichia coli, Klebsiella pneumoniae, and Proteus mirabilis isolates at a veterans medical center,” J. Clin. Microbiol., 38(5): 1791 1796, 2000

[39] M. Helmy, and R. Wasfi, "Phenotypic and molecular characterization of plasmid mediated AmpC ??-lactamases among Escherichia coli, Klebsiella spp., and Proteus mirabilis isolated from urinary tract infections in Egyptian hospitals,” BioMed. Res. Int., 171548, 2014

[40] A. Potron, L. Poirel, K. Elhag, F. Al Yaqoubi, P. Nordmann, "VEB-6 extendedspectrum - lactamase-producing Proteus mirabilis from Sultanate of Oman. Int,” J. Antimicrob. Agents 34:493-494, 2009.

[41] TS. Barrak, KA. Yasamin, and MA. Muhannad, "Molecular and bacteriologic Study of $\beta$-lactam Resistance Proteus mirabilis associated with Urinary Tract Infection in Holy Karbala province, Iraq,” J. Pharm. Sci. and Res. Vol. 10(3), 2018, 549-555, 2018 